\title{
Descrición do burro na sociedade galega: expresións figuradas galegas que retratan este animal
}

\author{
Andrea González Pereira ${ }^{1}$
}

Recibido: 28 de febreiro de 2021 / Aceptado: 15 de outubro de 2021

Resumo. O presente estudo, que forma parte dunha investigación fraseolóxica máis ampla, é unha análise de 72 expresións figuradas galegas construídas co referente animal de burro. Partimos da idea de que o ser humano conceptualiza certas situacións da súa vida cotiá, que lle resultan frecuentemente abstractas, a través da linguaxe figurada. Os referentes do mundo animal ocupan un lugar importante na creación de expresións figuradas, nas que o ser humano adoita verse animalizado para, dese xeito, comprender mellor determinadas realidades. A través da análise destas expresións, extraídas tanto de obras lexicográficas xerais e especializadas galegas coma da lingua oral, pretendemos coñecer a valoración que os galegos fan do burro, centrada en tres ámbitos temáticos: a caracterización do animal (tanto física coma moral), as relacións deste con outros animais e co ser humano e a valoración histórica do mesmo na sociedade galega. De xeito xeral, as valoracións de tipo negativo ocupan un lugar importante na caracterización do burro, mentres que as valoracións positivas e neutras teñen unha porcentaxe de aparición menor.

Palabras chave: expresión figurada; conceptualización; sociedade galega; animalización; burro.

\section{[es] Descripción del burro en la sociedad gallega: expresiones figuradas gallegas que retratan este animal}

Resumen. El presente estudio, que forma parte de una investigación fraseológica más amplia, es un análisis de 72 expresiones figuradas gallegas construidas con el referente animal de burro. Partimos de la idea de que el ser humano conceptualiza determinadas situaciones de su vida cotidiana, que le resultan frecuentemente abstractas, a través del lenguaje figurado. Los referentes del mundo animal ocupan un lugar importante en la creación de expresiones figuradas, en las que el ser humano suele verse animalizado para, de esta forma, comprender mejor determinadas realidades. A través del análisis de estas expresiones, extraídas tanto de obras lexicográficas generales y especializadas gallegas como de la lengua oral, pretendemos conocer la valoración que los gallegos hacen del burro, centrada en tres ámbitos temáticos: la caracterización del animal (tanto física como moral), las relaciones de este con otros animales y con el ser humano y la valoración histórica del mismo en la sociedad gallega. En general, las valoraciones de tipo negativo ocupan un lugar importante en la caracterización del burro, mientras que las valoraciones positivas y neutras tienen un porcentaje de aparición menor.

Palabras clave: expresión figurada; conceptualización; sociedad gallega; animalización; burro.

\section{[en] Description of the Donkey in Galician Society: Galician Figurative Expres- sions that Portray this Animal}

\begin{abstract}
The present study, which is part of a broader phraseological investigation, is an analysis of 72 Galician figurative expressions constructed with the animal reference of donkey. We start from the idea that the human being conceptualizes certain situations in his daily life, which are often abstract for him, through figurative language. The references of the animal world occupy an important place in the creation of figurative expressions, in which the human being is usually animalized to, in this way, understand better certain realities. Through the analysis of these expressions, extracted from both general and specialized Galician lexicographic works and from the oral language, we intend to know the valuation that the Galicians make of the donkey, focused on three thematic areas: the characterization of the animal (both physical and moral), his relations with other animals and with the human being and the historical valuation of it in Galician society. In general, negative type assessments occupy an important place in the characterization of the donkey, while positive and neutral assessments have a lower percentage of appearance.
\end{abstract}

1 Universidade de Vigo. Departamento de Filoloxía Galega e Latina.

Correo-e: andreagonzalezp@uvigo.es; ORCID: https://orcid.org/0000-0001-6183-0428. 
Keywords: Figurative Expression; Conceptualization; Galician Society. Animalization; Donkey.

Sumario. 1. Introdución. 2. A figura do burro en Galicia. 3. Metodoloxía de traballo. 3.1. Tipo de expresións seleccionadas. 3.2. Fontes de recolleita das expresións. 3.3. Criterios de presentación das expresións. 4. Expresións figuradas galegas construídas co referente do burro. 4.1. Caracterización. 4.1.1. Carácter/condición. 4.1.2. Características físicas. 4.2. Relacións. 4.2.1. Home-animal. 4.3. Valoración. 5. Recompilación e análise das enquisas. 6. Conclusións. 7. Referencias bibliográficas.

Como citar: González Pereira, A. (2021): "Descrición do burro na sociedade galega: expresións figuradas galegas que retratan este animal", en Madrygal. Revista de Estudios Gallegos 24, pp. 101-117, DOI: http://dx.doi. org/10.5209/madr.80236.

\section{Introdución}

A través do léxico dunha lingua os falantes expresan a súa visión particular do mundo que os rodea. Esta visión poderá ser diferente de acordo coa realidade que cada colectividade perciba, da cultura e das tradicións asociadas ó lugar onde habite e da época na que esta se atope.

As expresións figuradas serven de base para coñecer ben un pobo e unha cultura, posto que constitúen un reflexo fiel dos modos de vida de cada lugar, así como da súa historia. A través da linguaxe figurada, que ten como principal recurso a metáfora, o ser humano é capaz de comprender e de expresar determinadas realidades, que son frecuentemente abstractas, a través de imaxes concretas e facilmente recoñecibles por formaren parte da súa vida diaria:

We have seen that metaphor pervades our normal conceptual system. Because so many of the concepts that are important to us are either abstract or not clearly delineated in our experience (the emotions, ideas, time etc.), we need to get a grasp on them by means of other concepts that we understand in clearer terms (spatial orientations, objects etc.). (Lakoff e Johnson 1980: 115)

Unha destas realidades próximas para os galegos e que lles permite conceptualizar e expresar certas ideas é o ámbito animal. Partimos da premisa de que os animais representan en Galicia unha fonte rica de creación de expresións figuradas que axudan a comprender e expresar diferentes tipos de realidades, entre elas especialmente as de índole abstracta. Centrámonos, neste estudo, nas expresións figuradas que se forman mediante o emprego do burro como referente, aquelas que lles serven ós seres humanos para manifestar determinados sentimentos, desexos, estados, características físicas ou morais etc. Escollemos esta figura por ser un dos referentes animais cunha clara vinculación coa economía familiar de tantas/ os galegas/os de antano, un animal que estaba presente en moitos traballos agrícolas e que permitía sacar adiante as familias (xunto con outros coma a vaca ou o boi) ata o punto de converterse, ás veces, nun ben imprescindible no mundo rural galego.

\section{A figura do burro en Galicia}

O burro tal e como hoxe o coñecemos procede da domesticación da especie salvaxe Equus africanus, propia do norte de África (Perozo Ruiz 1999: 117), que se levou a cabo arredor do ano 3000 a. C. (Burnie 2002: 226). Todo parece indicar que, trala súa domesticación, se foi asentando en varios países de África ata chegar ós países da ribeira do Mediterráneo, polo que non tardou moito tempo máis en chegar ó noroeste peninsular (Mandianes 2002: 15). Unha vez domesticado, este animal empregouse en varios lugares do mundo.

En Galicia foi introducido como animal de carga, de monta, ou de forza tractora para os traballos agrícolas no século XIX, aínda que xa no século XVIII era común en terras castelás (Casal Vila 2003: s. v. burro). O antropólogo Manuel Mandianes (2002) explica a grande importancia que chegou a ter o burro na nosa comunidade e como, coa chegada de diversas maquinarias agrícolas, foi desaparecendo das casas galegas:

O burro, dende hai milleiros de anos ata os anos cincuenta, foi un punto de referencia para moitas xeracións, moi especialmente para os habitantes do mundo rural. Dende os anos cincuenta ata os nosos días, case desapareceu de moitos lugares, mesmo daqueles para os que fora un útil indispensable. Non só foi un referente necesario, un instrumento de traballo, un compañeiro do home, habitante de todos os camiños, senón tamén un soporte simbólico de realidades máis profundas, do que está detrás das aparencias: o lado visible dunha realidade invisible. $\mathrm{O}$ burro iniciou a súa retirada cos arados, os sachos, os carros e co tempo mítico perante a mecánica. Chegado un momento, o home moderno non tiña tempo para percorrer os camiños nin medir o tempo a ritmo de burro e abandonouno. (Mandianes 2002: 97)

A raza autóctona de Galicia denomínase burro fariñeiro (Groba Bouza 2011: 151) e o seu uso foi xeneralizado como medio de transporte, 
principalmente de gran e fariña, dende as casas ata os muíños de auga. Precisamente desa imaxe do animal cargado de fariña procede o nome de burro fariñeiro (Pose Nieto 2008: 307). Con todo, o burro levaba a cabo tamén outros labores, que podían ser diferentes dependendo do lugar da xeografía galega na que se atopase: en zonas do interior empregábase, ademais de para os traballos agrícolas, para a extracción de leña como animal de tiro; nas zonas urbanas eran os que axudaban as leiteiras a repartir o leite; e na costa usábase para a extracción de algas que despois se depositaban nos areais a xeito de fertilizante (Ibid.: 307). Hoxe en día estes labores caeron en desuso por distintos factores que lle son alleos ó animal (como a evolución nas ferramentas de traballo, ou o cambio de vida do rural ó urbano), pero que repercuten directamente no censo de burros que van quedando no noso país.

Actualmente son moi poucos os burros que existen en Galicia e, menos aínda, os exemplares da raza autóctona. A Asociación de criadores de cabalo de Pura Raza Galega (PuRaGa) estimou que entre os anos 2003 e 2004 existían en Galicia uns 180 exemplares de burro fariñeiro ${ }^{2}$. En 2012 conseguiron localizar entre 50 e 100 exemplares da raza fariñeira e, dende entón, tentan recuperala mediante cruzamentos para garantir a súa conservación. Ademais, como explica Pose Nieto (2008: 307), o burro tamén comezou a ser empregado, aínda que de xeito illado, como compañeiro en rutas turísticas, como montura para pequenas excursións e en actividades de asnoterapia.

Malia a situación que vive hoxe o burro en Galicia, tal e como o explica Groba Bouza (2011: 174), a pegada que este animal deixou na nosa lingua e na nosa cultura foi moi profunda, tanto que os galegos aínda o empregan como referente para conceptualizar a súa realidade cotiá a través de expresións figuradas.

\section{Metodoloxía de traballo}

\subsection{Tipo de expresións seleccionadas}

Para a creación deste corpus de traballo seleccionamos as expresións figuradas que se forman tomando o burro como referente. Recollemos expresións que nos permitisen extraer ideas sobre a visión que os galegos teñen deste animal. Todas elas presentan, pois, o burro como referente, xa sexa mediante unha alusión explícita en que se empregue o seu nome (burro cego), por alusións referidas ós ruídos que emite (ornear/orneo), a accións concretas realizadas polo animal (soltar un couce) ou por poñer de manifesto certos aspectos relacionados co trato que o ser humano lle deu durante anos (burro do xitano, en vendo o pau, alonga o paso).

Canto á morfoloxía, as expresións figuradas recollidas son de tipo variado en tanto que poden ser unidades monoverbais, constituídas por unha soa palabra, de distintas categorías gramaticais (burro/ornear), ou entidades fraseolóxicas pluriverbais, constituídas por dúas ou máis palabras (burra aceiteira / burro de carga / chámalle burro ó cabalo! / o que lava a cabeza da burra perde o xabón e a lavadura).

As expresións recollidas co burro como referente refírense a aspectos do seu comportamento, o que as persoas interpretamos como carácter ou condición do animal, á relación que existe entre o home e o animal e a aspectos que dan indicios da valoración que facemos os galegos do animal. De acordo con isto, optamos por omitir as expresións nas que se fai referencia á súa morte, a aspectos biolóxicos ou a enfermidades comúns nel.

A grande maioría das expresións figuradas que aquí recollemos caracterízase, ademais, por implicar a animalización ou zoomorfización do ser humano nun burro, isto é, establécese unha relación entre a aparencia, as actitudes e o comportamento do animal e as persoas. Nestas unidades, chamadas zoomorfismos, dáse un proceso de metaforización ó aplicarlle as calidades propias dun animal a un ser humano (Cruz Cabanillas e Tejedor Martínez 1998: 383). Estes zoomorfismos distínguense, xa que logo, por empregar o nome dun animal en sentido figurado para caracterizar unha persoa a través da metáfora conceptual AS PERSOAS SON ANIMAIS.

\subsection{Fontes de recolleita das expresións}

A recolleita das expresións figuradas levámola a cabo a partir do baleirado de refraneiros e dicionarios especializados en fraseoloxía galega, para despois completar a información cos dicionarios de carácter xeral. Os primeiros 
foron o Refraneiro galego básico (Ferro Ruibal 1995) (RGB), o Refraneiro galego máis frecuente (Ferro Ruibal 2002) (RGMF), o Dicionario fraseolóxico galego (Martínez Seixo 2000) (DFXG); o Dicionario fraseolóxico do mar (Rivas López 2005) (DFXM), o Dicionario de fraseoloxía galega (López Taboada e Soto Arias 2008) (DFG) e a achega feita por Ferro Ruibal (2006), en forma de artigo, de 9713 "Locucións e fórmulas comparativas ou elativas galegas" (LFCEG), extraídas do Tesouro Fraseolóxico Galego (TFG).

Consideramos importante o baleirado de dicionarios xerais para poder localizar expresións figuradas monoverbais que, en principio, non adoitan aparecer en dicionarios fraseolóxicos, así como, no seu caso, para completar o repertorio fraseolóxico extraído dos dicionarios especializados. Para esta busca escollemos o Gran dicionario Xerais da lingua (Carballeira Anllo, 2009) (GDXL), editado en papel con 100.000 entradas e que ofrece un amplo abano de elementos fraseolóxicos. Despois, fixemos a mesma busca no Dicionario da Real Academia Galega (2012) (DRAG), editado de xeito dixital e composto por 50.000 entradas $^{3}$ (no momento de extracción das expresións). Nestes dicionarios xerais tamén buscamos voces creadas a partir da raíz do nome do animal e que posúen un sentido figurado: burrada.

Co obxectivo de atopar outras expresións figuradas que se referisen de maneira indirecta ó burro, acudimos ó Dicionario conceptual galego (Quintáns Suárez 1997) (DCG). Deste xeito puidemos atopar outros usos figurados con este referente animal mediante unha nova busca nos refraneiros e dicionarios antes citados e completar as expresións figuradas extraídas de fontes escritas (por exemplo, con expresións como ornear ou orneo para referirse a accións que realiza o ser humano).

Aínda que empregamos estas obras como fonte de información para a extracción das expresións, utilizamos tamén outras para contrastar e interpretar aquelas que en principio nos resultaron dubidosas. Buscamos estas construcións en refraneiros como o Refraneiro galego e outros materiais da tradición oral (Vázquez Saco 2003), o Refraneiro galego
(Taboada Chivite 2000) e nos dicionarios de carácter xeral que se recollen no Dicionario de dicionarios $^{4}$ (Santamarina Fernández 2003).

Posto que consideramos que a oralidade é o contexto principal de uso das expresións figuradas, decidimos crear unha enquisa fraseolóxica que nos permitise recoller expresións novas co referente animal burro ou variantes daquelas que xa posuïamos mediante o baleirado dos dicionarios anteriormente citados. Realizáronse en total 300 enquisas, das que 250 foron de carácter electrónico (mediante unha plataforma web) e 50 de carácter oral (a través do contacto persoal cos/coas informantes).

\subsection{Criterios de presentación das expresións}

O número total de expresións recollidas co burro como referente en galego foi de 72 (10 expresións monoverbais; 18 locucións non comparativas; 20 locucións comparativas; 18 refráns; 3 fórmulas; 3 dialoxismos).

Presentamos as ditas expresións desagregadas en tres ámbitos temáticos xerais que representan a opinión que teñen os galegos do animal: aspectos referidos ó seu carácter e/ou condición, características físicas que destacan del e relacións que se dan entre o burro e o ser humano ou entre o burro e outros animais. Dentro de cada un destes tres ámbitos temáticos xerais, existen outros subámbitos que concretan tematicamente cada expresión.

O significado que se ofrece en cada unha das expresións é figurado, aquel que empregamos frecuentemente para extraer o ámbito temático en que situamos a unidade. Para conseguir o significado figurado idóneo en cada caso, adoitamos transcribir aquel que se ofrece na obra da que foi tirada a expresión. Cando unha mesma expresión se rexistra en máis dunha fonte, escollemos para a nosa táboa o significado que cremos que achega unha información máis completa e clara. Nestes casos, as siglas da obra da que foi tirada a definición márcanse en letra grosa. Para os casos en que non atopamos ningunha definición axeitada da expresión -etiquetas xenéricas nas obras consultadas ou imprecisión de significado nas enquisas- buscamos noutras fontes que non

\footnotetext{
Aínda que o número de entradas é menor ca no dicionario anterior, consideramos importante o seu baleirado por ter carácter académico.

4 Para coñecer máis sobre estas obras poden verse os prólogos respectivos incluídos neste dicionario en: http://sli. uvigo.gal/DdD/documentos/ddd_prologos.pdf.
} 
fosen consultadas previamente (refraneiros e dicionarios galegos ou doutras linguas próximas, artigos, blogs...) e que nos puidesen achegar unha definición adecuada para a expresión; indicamos a fonte orixinal cunha nota ó rodapé. No caso de non atopar ningunha definición adecuada mediante esta busca, facemos unha paráfrase do seu significado baseada nas nosas lecturas e no noso coñecemento cultural. Especificamos que o significado que ofrecemos é noso mediante un asterisco (*) ó comezo da definición.

A seguir presentamos as expresións figuradas ordenadas alfabeticamente en cada un dos subámbitos temáticos, xunto co seu significado figurado e a obra ou obras das que foron extraídas. No caso de que se extraeran dunha enquisa electrónica (EE) ou oral (EO), tamén se especifica.

\section{Expresións figuradas galegas construídas co referente do burro}

\subsection{Caracterización}

\subsubsection{Carácter/condición}

A característica da estulticia é a que destaca con diferenza sobre os demais trazos relativos ó carácter ou á condición do burro nas expresións figuradas analizadas. Nas seguintes expresións prodúcese a animalización do ser humano nun burro mediante o emprego da metáfora conceptual A PERSOA ESTULTA É UN BURRO:

- [tan listo/esperto] coma un burro: * 'pouco listo, pouco intelixente' (LFCEG)

- asno/burro/burrico/burricán: 'que ten poucos coñecementos ou ten dificultades para comprender as cousas' (DRAG, GDXL, EO)

- burra aceiteira: '[ironicamente] ter poucas luces' (GDXL)

- burro cego: 'persoa moi pouco intelixente, moi torpe ou parva' (DFXG, GDXL)

- burro lavado, xabón perdido / o que lava a cabeza da burra perde o xabón e a lavadura: * 'fai referencia a un esforzo inútil, normalmente relacionado co feito de querer instruír unha persoa estulta ou alguén que se nega a recibir calquera tipo de ensinanza' (RGMF, RGB)

- chámalle burro ó cabalo!: 'dise ironicamente para se referir a alguén que aparenta ser máis parvo do que é' (DFG, DFXG, EE)

- ir de burra e volver de albarda: 'non aprender nada' (DFXG, GDXL)
- máis vale burro vivo ca sabio morto: * 'refírese a que é mellor conformarnos co que temos' (RGMF, RGB)

- picar de burro para besta: 'úsase para ponderar a ignorancia de alguén' (DFG)

- val máis pan duro que consello de burro: * 'aconsella non facer caso a alguén pouco intelixente' (RGMF, RGB)

Do mesmo xeito, os ruídos propios dun burro vehiculan, tamén, o valor da estulticia:

- orneadas/orneos/palabras/patadas de burro non chegan ó ceo: 'dise cando alguén di unha parvada ou tenta ofender ou molestar, para dar a entender que non se lle fai caso' (DFXG, RGB, EE)

- ornear: 'dicir burradas en voz alta' (GDXL)

Rexistramos, ademais, outras expresións que xorden da conceptualización de accións ou actos propios de persoas ignorantes a través da imaxe do burro:

- burrada/asnada/asneira: 'dito ou feito que é mostra de ignorancia ou de pouca intelixencia' (DRAG, GDXL)

- burrería: 'realizar un acto propio de persoas pouco sabidas' (DFXM)

Ademais, localizamos unha expresión non animalizadora coa que se caracteriza o burro como estulto a través dunha personificación, en que se lle atribúen características propias do ser humano ó burro, neste caso o razoamento:

- pensando morreu un burro: 'dise cando convén actuar e non seguir perdendo o tempo en pensamentos varios' (DFG)

A característica da intelixencia, así coma outras características morais ou mentais do ser humano, adoita estar vinculada cunha serie de imaxes metafóricas que veñen dadas a través de características físicas. Para o ser humano, as persoas intelixentes son aquelas que máis rápido comprenden as cousas, de xeito que unha mente áxil e rápida é unha mente privilexiada e que sobresae por riba das demais. A rapidez mental asóciase coa rapidez física, de maneira que os animais máis veloces son considerados intelixentes:

La rapidez con que las personas inteligentes comprenden aquello que ven o que se les explica determina que este rasgo sea recurrente en la caracterización de los individuos con alto nivel 
de inteligencia. A este respecto, son frecuentes las correlaciones o las comparaciones con elementos o animales rápidos, tanto para designar la misma agudeza mental (chispa) como, sobre todo, para hacer referencia al individuo inteligente. (Álvarez de la Granja 2011: 387)

Mais o burro non é un animal que se caracterice polos seus movementos veloces, senón por levar un paso lento. Así, do mesmo xeito que a rapidez mental se asocia coa rapidez física, a lentitude física asóciase coa lentitude mental. Por iso, os animais de movementos lentos, como é o caso do burro, adoitan ser caracterizados como estultos polo ser humano.

Por outra parte, tamén o campo semántico da visión se adoita asociar directamente co da intelixencia, cando aquela é boa, e coa estulticia, en caso de falta ou escaseza. Así, a agudeza visual é interpretada como agudeza intelectual a través da metáfora conceptual A COMPRENSIÓN INTELECTUAL É VISIÓN (Santos Domínguez e Espinosa Elorza 1996: 126). Os seres humanos concibimos frecuentemente a intelixencia como luz, de maneira que aquel que é lúcido, clarividente ou que ten as ideas claras é unha persoa intelixente (Álvarez de la Granja 2011: 387). Posto que COMPRENDER É VER, as persoas crean expresións como $x a$ vexo o que me dis para indicar que entenden algo. Do mesmo xeito, a persoa que ten poucas luces será alguén estulto, polo que se está a conceptualizar a realidade da estulticia a través da metáfora conceptual antagónica NON COMPRENDER É NON VER (Santos Domínguez e Espinosa Elorza 1996: 129). A partir dela, créanse outras expresións como non vexo o que me estás a dicir para indicar que non se comprende nada ou ten unha venda diante dos ollos para indicar que algo impide coñecer a verdade. Polo que se refire ó campo semántico dos animais, en galego existen expresións figuradas que empregan o referente da aguia, un animal de excelente agudeza visual ${ }^{5}$, para representar a intelixencia e a toupeira, que pacede atrofia nos ollos', para a estulticia: aguia ('persoa de moita perspicacia e viveza' GDXL) e toupa/ toupeira ('persoa pouco espelida' GDXL). No caso concreto do burro, atopamos a expresión burro cego, en que se reduplica a referencia á estulticia mediante o adxectivo cego.

Piñel López (1999: 414) explica, nun estudo contrastivo de refráns que se constrúen con animais en castelán e alemán, que o burro é o animal que protagoniza o maior número de refráns nas dúas linguas analizadas; principalmente en castelán, di, "debido al papel tan importante que ha desempeñado durante siglos en las tareas agrícolas, sobre todo en las zonas más deprimidas y pobres que no podían adquirir caballos y en las que los asnos cumplían las labores propias de los caballos". A autora comproba que o burro serve de referente para a construción de expresións maioritariamente negativas nas que destaca o valor da ignorancia e da obstinación. Explica a autora que o burro é o animal prototípico para representar a estupidez ${ }^{7}$, e que o seu nome se emprega en case todos os idiomas como insulto dirixido ás persoas que presentan pouca lucidez mental ou pouco entendemento.

Como acabamos de ver, os galegos tamén empregan este animal para crear expresións que denotan a estulticia. O motivo polo que escollen o burro de xeito maioritario entre os que se atopan no espazo doméstico podería vir dado por dúas vías. Por unha banda, e de acordo co indicado, o burro convértese en referente da estulticia pola súa lentitude física. Por outra banda, podemos acudir á interpretación que fan os galegos do comportamento do burro. Veno como un animal dócil, que se acomoda a todas as tarefas domésticas sen opoñer resistencia, sen envorcar a carga que transporta; e que a pesar do maltrato que sofre por parte dos seus amos (vid. infra) tampouco tenta escapar cando anda solto (Mandianes 2002: 60). Deste xeito, interpretan o seu comportamento como estulto, e por iso crean expresións nas que serve como referente para caracterizar alguén pouco intelixente e sen vontade propia ${ }^{8}$. Así o explica, tamén, Piñel López (1999: 414) para o castelán: "Representa la ignorancia, madre de la obstinación. Estúpido y obstinado, le da

\footnotetext{
DRAG, 2012: s.v. aguia.
}

GDXL, 2009: s.v. toupeira.

Chevalier (1988: 144) destaca que o burro é o símbolo da ignorancia na cultura occidental.

Mariño Ferro (1996: 36) explica que o asno na cultura occidental está considerado equivocamente como un ser estúpido. Isto débese, di, ó feito de que "soporta ser despreciado y apaleado toda su vida, en gran parte debido a su lentitud". Ademais, engade que no Bestiario de Oxford o animal descríbese como lento e desprovisto de intelixencia, de maneira que a súa lentitude física se relaciona directamente coa lentitude mental coa que o caracterizan as persoas. 
lo mismo lo bueno que lo malo, se muestra insensible a los golpes o a los reproches, a diferencia de los restantes animales".

Pero aínda que o burro funcione como referente da estulticia, o certo é que é un animal dotado de intelixencia pois, tal e como explica Mandianes (2002: 88), todos os asnos poden ser domados facilmente para o paseo, son capaces de responder ó seu nome e, ademais, gozan coa compaña das persoas, sinais que mostran, segundo o autor, a intelixencia deste animal. Así o explicou, tamén, Cascajero Garcés (1998: 15) nun estudo que realizou sobre a simboloxía do burro na antigüidade a través de fontes escritas e orais do castelán. Nel, o autor apunta que a intelixencia do burro tende a facer que o seu adestramento sexa máis complexo que o do cabalo ou o do mulo. As fases do proceso de aprendizaxe do burro son máis rápidas que as dos outros dous animais, polo que as excesivas repeticións rematan por aburrilo e frustralo. Esta actitude, segundo explica o autor, é interpretada polo adestrador inexperto como estulticia do animal, polo que o culpa a el dos seus propios fracasos.

Aínda que non rexistraramos en galego ningunha expresión figurada en que se tome o burro como referente da intelixencia, os galegos tamén o caracterizan, como se poderá ver ó final deste artigo, como un animal intelixente (aínda que nun número de veces inferior á característica da estulticia). Esta idea está presente noutras linguas como o castelán (Martín Zorraquino 1986: 1261) ou o ucraíno (Vyshnya e García Jove 2005: 194) en que se levaron a cabo estudos sobre as expresións construídas con este animal e nas que o burro simboliza a estupidez, pero tamén a intelixencia.

Relacionada coa ignorancia e a estulticia atopamos a característica da teimosía/insistencia. Tal e como explica Piñel López (1999: 414) a ignorancia é a nai da obstinación, polo que alguén ignorante adoita ser obstinado e teimudo. A autora apunta que o burro é normalmente considerado polas persoas un animal teimudo, xa que entenden, a partir da observación do seu comportamento, que resulta inútil calquera acción por parte do ser humano para que mude de parecer (Id.). Groba Bouza (2011: 157) indica que a ignorancia e mais a teimosía son características que se lle adoitan atribuír tanto ó burro coma á mula, e especifica que son dous aspectos da interpretación do comportamento equino que máis fraseoloxía teñen producido en galego.

As seguintes expresións resaltan a teimosía ou insistencia do burro e nelas dáse a animalización do ser humano nun burro mediante a metáfora conceptual A PERSOA TEIMUDA/INSISTENTE É UN BURRO. Os referentes que o ser humano escolle para a creación destas expresións son os ruídos e o propio animal:

- [testudo/terco/testón/teimoso/testán/testarudo] coma unha burra/ coma un/os burro/s: 'ser moi testudo' (DFG, LFCEG, EE, EO)

- non levarán por ben o burro á auga, se el non ten gana: * 'refírese a que non se pode convencer a alguén de algo cando se nega a facelo' (RGB)

- (e) a burra déitase!: * 'dise cando alguén se deita ou se rende" ${ }^{\prime 9}$ (EO)

- ornear: 'chorar ou queixarse sen parar' (GDXL, DRAG)

Noutras ocasións o proceso de animalización do ser humano nun burro dáse a través da metáfora conceptual OS SENTIMENTOS, ESTADOS DE ÁNIMO, PENSAMENTOS E FACULTADES MENTAIS SON ANIMAIS (Echevarría Isusquiza 2003: en liña), que para este caso concreto se subespecificaría como OS SENTIMENTOS, ESTADOS DE ÁNIMO, PENSAMENTOS E FACULTADES MENTAIS SON UN BURRO:

- baixar da burra / caer da burra / caer do burro (abaixo/embaixo): 'decatarse do erro no que se estaba; caer na conta, por fin, de algo que non se daba entendido' (DFG, DFXG, DFXM, DRAG, GDXL, EE, EO)

- baixar da burra [a alguén]: 'convencer de algo a alguén que estaba obstinado no contrario' (DRAG)

- coller/ter o burro: 'incomodarse' (DFXG, GDXL)

A agresividade é outra das características que os galegos destacan no animal. Trátase dun trazo que quizais garde relación coa súa teimosía, pois baséase no comportamento do animal cos seres humanos: en ocasións pode volverse agresivo cando non quere seguir as ordes do amo ou simplemente se incomoda 
por algo. Sirvan de exemplo as seguintes expresións en que o ser humano se animaliza nun burro a través da metáfora conceptual A PERSOA AGRESIVA É UN BURRO:

- [dar un couce] coma unha burra / [dar couces] coma os burros: 'dise cando unha persoa fai algo malo a outra que non o esperaba' (DFXG, LFCEG, GDXL, EE)

- amor dos burros entra a couces e a dentadas: * 'fai referencia ás relacións amorosas difíciles' ${ }^{10}$ (RGB)

- chanzas con burros acaban en couces: * 'refírese a que cando se fan bromas con determinadas persoas, a situación pode acabar mal' (RGB)

Como se pode comprobar, en todas as expresións que caracterizan o burro como agresivo destacan os seus couces, que son o recurso habitual que empregan estes animais para defenderse, tal e como explica Mariño Ferro (1996: 38).

O carácter falso co que os galegos caracterizan o burro, e máis concretamente a burra, pode gardar relación coa agresividade do animal, de maneira que dá couces cando un menos o espera (Groba Bouza 2011: 157). Así construímos expresións como [falso] coma unha burra vella / [máis falso] ca unha burra vella ('hipócrita') (GDXL, EE, EO) en que animalizamos o ser humano nunha burra a través da metáfora conceptual A PERSOA FALSA É UNHA BURRA. Cremos, ademais, que nestas expresións ten especial importancia o adxectivo vella, pois acrecenta a valoración concreta que os galegos fan do animal na expresión, neste caso a falsidade.

Outro ámbito que garda relación coa agresividade do animal, pero tamén co seu gran tamaño, que lle proporciona a forza necesaria para os traballos no campo, é o da rudeza/brutalidade. Os galegos crean expresións como burrada ('acción bruta ou inhumana') (GDXL) ou burro ('persoa falta de delicadeza e amabilidade') (GDXL) en que se animaliza o ser humano e as súas accións na figura e nas accións dun burro a través da metáfora conceptual A PERSOA BRUTA É UN BURRO.
Pero a pesar de que o burro sexa caracterizado polos galegos como un animal agresivo e bruto, tamén lle apoñen a característica de manso. Con relación a este valor, Ferreira Guerra (2011: 413) explica que os burros simbolizan a paz e a mansedume na tradición cristiá e apunta que foron dúas as circunstancias que contribuíron para que se creara este simbolismo: a viaxe que fixo María a Belén nun burro nos últimos momentos do seu embarazo e a entrada triunfal de Xesús, xa adulto, en Xerusalén o Domingo de Ramos, montado tamén nun burro. Cremos que esta valoración, ademais, está vinculada co feito de ser o burro un animal que, normalmente, non opón demasiada resistencia ós traballos que lle encomenda o seu amo (Mandianes 2002: 60); aínda que, como observamos, cando si o fai é caracterizado como agresivo. Así, temos a expresión galega non morrer da cornada dun burro ('dise de quen toma moitas precaucións') (DFG), que pon de relevo a mansedume do animal, ó establecer un contraste entre este e o acto violento da cornada, que o burro, por razóns obvias, é incapaz de dar.

Relacionada cos traballos agrícolas para os que se empregaba o burro en Galicia atopamos a característica da laboriosidade na expresión burro $^{11}$ ('persoa moi traballadora') (GDXL), que animaliza o ser humano nun burro a través da metáfora conceptual A PERSOA QUE TRABALla É UN ANIMAL (Iñesta Mena e Pamies Bertrán 2002: 217) e, máis concretamente, A PERSOA QUE TRABALLA É UN BURRO.

O burro tamén funciona en galego como referente da gula para a creación de expresións figuradas. Pode facelo mediante alusións implícitas ó tamaño do animal, coma no caso de [cheo] coma un burro (* 'fai referencia á fartura despois de comer en abundancia') (EE), en que se produce unha animalización do ser humano a través da metáfora conceptual $\mathrm{O}$ QUE COME MOITO É UN ANIMAL (Iñesta Mena e Pamies Bertrán 2002: 166), un burro concretamente. Ou tamén pode funcionar como referente da gula mediante expresións que denotan un comportamento lambón do animal:

10 Groba Bouza (2011: 157) explica que o cortexo equino semella unha acción violenta, pois antes da cópula pode haber couces e mordeduras entre macho e femia. Ademais, engade tamén que cando os animais se atopan en liberdade os sementais loitan ata a extenuación por seren os que cubran as femias.

11 Existen outras expresións no noso corpus en que o burro funciona como referente secundario do traballo ([cargar/ traballar] coma un burro); pero por ser o 'maltrato' do home sobre o animal o referente primario das expresións figuradas, estas serán analizadas no apartado correspondente ó 'maltrato'. 
- alá vai o burro coas noces!: 'expresión de forte contrariedade cando algo é desbaratado’ (DFG)

- dixolle o burro ás coles: pax vobis!: * 'fai referencia ó asoballamento entre clases sociais' (RGMF, RGB)

- voltou a burra ó trigo!: * 'fai referencia a que unha persoa actúa igual de mal ca outra ou que un feito é igual de inconveniente ca outro' (EE)

Por último, existe unha expresión no noso corpus en que a burra funciona como referente da fortuna: vir a burra branca co diñeiro ('vir a fortuna') (GDXL). Cremos que a explicación para esta expresión figurada podería estar en dous tipos de motivación: a intertextual, en que estarían presentes referencias relixiosas, e a icónica, en que se destacaría a cor non habitual do animal.

Na Biblia observamos que o burro era un animal moi apreciado polos hebreos, unha cabalería rexia por excelencia. No libro da Xénese (49) descríbese a escena da chegada do rei dos xudeus montado nun burro; por outra parte no evanxeo de San Marcos (11) retrátase a chegada de Xesús a Xerusalén montado nun burro, mais non como símbolo de humildade ou pobreza, senón como un símbolo real, polo apreciado do animal. No evanxeo de San Mateo (2) observamos que é un burro o que transporta a Xesús meniño na súa fuxida a Exipto por mor da matanza de nenos que está a levar a cabo Herodes, e polo tanto o animal asóciase á boa sorte de Xesús. O burro vincúlase, tamén, coa relixión cristiá polas marcas que ten no corpo. Tal e como explica Benavente Jareño ${ }^{12}$, os burros teñen un listón negro ou escuro ó longo do espiñazo, que se cruza con dúas bandas negras que baixan polo centro das escápulas, formando unha cruz nas agullas. Mariño Ferro (1985: 89) sinala que certas crenzas cristiás explican que esa cruz apareceu no lombo do animal dun xeito misterioso despois da entrada de Xesús en Xerusalén montado nun animal desta clase $^{13}$. O autor engade que, en Dorsetshire (hoxe coñecido como Dorset, no suroeste de Inglaterra), curaban a tose convulsiva dando paseos en burro debido ó poder de curación que posuía a cruz do lombo do animal. Todos estes datos mostran o aprecio dos cristiáns polo burro e a boa sorte coa que o asocian.

Polo que se refire á cor do animal, tal e como explicamos anteriormente, os burros son ordinariamente de pelo gris e só adoitan presentar algún recuncho de pelo branco (no bandullo ou na contorna dos ollos), de maneira que o feito de atopar unha burra branca é algo tan infrecuente que queda asociado á boa sorte $^{14}$ ou á fortuna (Ferro Ruibal e Benavente Jareño ${ }^{15}$ ). Por outra parte, existiría tamén unha oposición simbólica da pobreza vs. a fortuna (agora asociada co diñeiro), xa que o burro é o animal das casas galegas sen recursos, por tratarse dunha cabalaría barata e que non supón grandes custos para o seu mantemento (en contraposición ó cabalo, por exemplo). Xa que logo, o feito de que sexa unha burra branca a que "veña co diñeiro", e non unha burra torda como é o habitual, deixa ver o extraordinario da expresión: o burro só funciona como referente da fortuna cando non ten a súa aparencia habitual. Por último, non debemos esquecer os valores positivos que adoita portar a cor branca na cultura occidental fronte a outras cores máis escuras, coma a negra, que se asocian a aspectos negativos (Szalek 2005: 89). Proba disto son, por exemplo, expresións galegas como branquear ('converter en legal o diñeiro conseguido en actividades ilícitas'16), en que o branco se identifica co legal, ou estar negro ('estar ou considerar algo difícil, ter ou verlle poucas posibilidades de solución' ${ }^{17}$ ). Tal e como explica Szalek (Ibid.: 90), a cor branca simboliza, en termos xerais, a luz, a pureza, a bondade, a inocencia e a boa sorte, mentres que o negro é a cor do sombrío, do impuro, do mal, do pesimismo, da mala sorte, da morte etc. Cremos que estes valores simbólicos asociados ó branco tamén están representados na expresión vir a burra branca co diñeiro.

Comunicación persoal co autor.

3 A cruz está presente noutros animais da mesma especie (coma o cabalo ou a mula), pero tal e como explica Mariño Ferro (1996: 38): "En el burro esa cruz está especialmente marcada y representa la cruz de Cristo".

14 En galego existen outras expresións figuradas en que un animal, polo feito de ter outra cor non habitual nel, funciona como referente de significados positivos: merlo branco 'ser unha persoa moi boa' (GDXL).

15 Comunicación persoal cos autores.

16 GDXL, 2009: s.v. branquear.

17 DRAG, 2012: s. v. negro. 


\subsubsection{Características físicas}

Unha das características físicas nas que reparan os galegos cando crean expresións figuradas co burro como referente é a súa grandura, ou a grandura de certas partes do seu corpo. Nas seguintes expresións figuradas o ser humano vese animalizado nun burro a través da metáfora conceptual A PERSOA GRANDE É UN BURRO e A PERSOA QUE TEN AS ORELLAS/A BOCA GRANDE/S É UN BURRO:

- [botar/ter orellas] coma unha burra / [ter (as) orellas (grandes)] coma un burro: * 'ter as orellas moi grandes' (LFCEG)

- [grande] coma un burro: 'gordura' (LFCEG, EE)

- [ter a boca] coma un burro: 'boca grande'(LFCEG)

Atopamos, por outra parte, a personificación do animal na seguinte expresión en que se lle atribúen ó burro funcións propias do ser humano, como a fala. Nesta expresión séguese destacando a grandura do animal, concretamente das súas orellas, mediante a comparación con outros animais similares:

- díxolle o burro ó mulo jtírate alá orelludo!: * 'refírese a que non se pode criticar a alguén cando se teñen os mesmos defectos' (RGB)

Existe, tamén, outra expresión figurada en que non se dan procesos de animalización nin de personificación, pero na que este animal segue a funcionar como referente da grandura:

- non ver un burro a tres/catro pasos: 'haber moi pouca ou nula visibilidade ${ }^{18}$ (DFG, GDXL)

A partir da grandura do burro desenvólvense outras metáforas que relacionan cantidades significativamente grandes de algo co tamaño deste animal:

- burrada: 'cantidade moi grande' (GDXL, DRAG)

- coma un burro: 'moito' (GDXL)

Outros dous valores que destacan os galegos do burro son a resistencia e a fortaleza. O burro é para os galegos un animal resistente e útil para os traballos que requiren forza tractora, firmeza para levar grandes pesos e, sobre todo, capacidade de aguantar grandes esforzos. Cascajero Garcés (1998: 15) explica que os burros son máis lonxevos e máis resistentes ás enfermidades cós cabalos; ademais, son superiores a eles tamén na resistencia á fatiga porque teñen máis enerxía. Esta resistencia no animal maniféstase na expresión galega [ter a saúde] coma un burro ('saúde boa') (LFCEG), en que o ser humano se ve animalizado en burro mediante a metáfora conceptual A PERSOA RESISTENTE/CON BOA SAÚdE É UN BURRO. Do mesmo xeito, a grande forza do animal para cargar grandes pesos ${ }^{19}$ é a que motiva a expresión [ter unha forza] coma un burro (* "ter moita forza') (EO) en que o ser humano se animaliza nun burro a través da metáfora conceptual A PERSOA FORTE É UN BURRO.

Tamén os ruídos que produce o animal, fortes orneos, que son molestos e estridentes para os oídos do ser humano (Mariño Ferro 1996: 38), funcionan como referentes na creación de expresións figuradas en que se adoita producir a animalización da persoa nun burro mediante metáforas conceptuais como A PERSOA QUE BERRA É UN BURRO, A PERSOA QUE SE QUEIXA É UN BURRO OU A PERSOA QUE DI COUSAS SEN SENTIDO É UN BURRO:

- [berrar/griñir] coma un/os burro/s: * 'berrar forte' (LFCEG)

- ornear: 'chorar ou queixarse sen parar' (GDXL, DRAG)

- ornear: 'dicir burradas en voz alta' (GDXL)

- orneo: 'choro alto e sen motivo' (GDXL, DRAG)

Por último, o burro é un animal que funciona para os galegos como referente da fealdade. Xa sexa polas súas orellas desproporcionadas, a súa grande boca ou os seus movementos torpes, en galego, pero tamén noutras linguas coma o alemán e o castelán (Piñel López 1999: 414), o ser humano adoita verse animalizado nun burro para expresar a gran fealdade de alguén (A PERSOA FEA É UN BURRO):

- [(tan) feo] coma un burro: 'fealdade' (LFCEG)

18 O gran tamaño do seu corpo serve para reforzar, nesta expresión figurada concreta, o significado de 'falta de visibilidade' (Groba Bouza 2011: 151).

19 Poden verse ó respecto as expresións catalogadas baixo a etiqueta 'maltrato', que presentan a imaxe do animal cargando grandes pesos. 


\subsection{Relacións}

Canto ás relacións do animal, non rexistramos ningunha expresión figurada que tivese como referente a relación que se establece entre este e outros animais, pero si localizamos en galego expresións figuradas que teñen como referente a relación que se dá entre o home e o burro. Como mostraremos a continuación, existen dous subámbitos temáticos dentro das relacións home-animal que serven de referentes para a creación de expresións figuradas.

\subsubsection{Home-animal}

Entre as relacións que se dan entre o ser humano e o burro destaca, cun número elevado de expresións figuradas, o maltrato que o primeiro exerce sobre o segundo, de maneira que, en moitas destas expresións, o ser humano se ve animalizado nun burro mediante metáforas conceptuais diversas. Nas seguintes expresións o maltrato que o home exerce sobre o burro preséntase de maneira indirecta, mediante referencias ó traballo realizado por este animal e ós seus resultados:

A PERSOA MOI CARGADA/QUE TRABALLA SEN DESCANSO É UN BURRO:

- [(andar/ir) cargado] coma un burro: 'moi cargado' (DFXG, LFCEG, EE, EO)

- [cargar] coma un burro: 'pescar moito' (DFXM)

- [cargar/traballar] coma unha/un burra/burro: 'moito e moi duramente' (DFG, DFXG, EE, EO)

- burro de carga: "persoa que traballa moito e moi duramente' (DFG, GDXL)

- sofre o burro a carga mais non a sobrecarga: * 'fai referencia a que a resistencia, tanto física coma mental, ten os seus límites e pódese chegar ó esgotamento se se cometen excesos' (RGB)

A PERSOA CANSA É UN BURRO:

- [canso] coma un burro: * 'moi canso' (EE)

- burro cansado: 'persoa con pouco ánimo para emprender algo' (DFXG, GDXL)

Nas seguintes expresións, o maltrato do burro preséntase de forma directa a través da imaxe da persoa maltratando o animal. Ademais percíbese a animalización do ser humano a través da metáfora conceptual A PERSOA MALTRATADA É UN BURRO:

- [moucir] coma nun burro: 'golpear' (LFCEG)

- [ser] coma o burro do arrieiro: 'abuso' (LFCEG)

- cando o burro vén ó lugar todos o queren montar: 'abuso' (RBG)

Rexistramos, tamén, outras expresións galegas que non se basean directamente nas metáforas conceptuais citadas, pero nas que se inclúen imaxes que amosan o maltrato do animal:

- a burro frouxo, arrieiro tolo que lle malle o lombo: * 'aconsella tratar de malas maneiras as persoas de comportamento difícil, faltas de delicadeza, para que reaccionen' (RGB)

- a burro pardo, arrieiro arroutado: * 'aconsella tratar de malas maneiras as persoas de comportamento difícil, faltas de delicadeza, para que reaccionen' (RGMF, RGB)

- burro do xitano, en vendo o pau, alonga o paso: * 'refírese a que aqueles que están advertidos polas malas experiencias pasadas saben como actuar nas futuras' (RGB)

- non poder dar no burro e dar na albarda: 'castigar o inocente por non se atrever co culpable' (GDXL)

- o que non pode mallar no burro, malla na albarda: 'abuso' (RGMF)

Piñel López (1999: 414) destaca, tamén, a presenza do maltrato inflixido polos seres humanos sobre o burro na análise comparativa que realiza das expresións construídas con referentes animais en español e alemán. A autora explica que, ante a imposibilidade de que o burro aprenda ou obedeza (posto que, como observamos, é considerado un animal estulto e teimudo), a sabedoría popular aconsella o uso da violencia ${ }^{20}$, algo que aconteceu tamén na cultura galega.

Pero os galegos sempre foron ó tempo conscientes da utilidade deste animal. Como xa comentamos, o burro é un animal de grandes dimensións, forte e resistente; un animal que poucas veces opón resistencia ás ordes do seu amo e, polo tanto, que realiza os traballos impostos facilmente e mellor cós outros animais. O burro era útil noutrora para dúas

20 Cascajero Garcés (1998: 16-31) apunta que o burro se converteu xa dende a antigüidade nun símbolo de explotación en España. O autor sinala que dende sempre os campesiños explotaron ó máximo as prestacións do burro nas tarefas cotiás, ata tal punto que o mundo antigo non se podería concibir sen eles. 
funcións básicas: a forza tractora no campo e o transporte de alimentos ou persoas (se non había cabalos). Ademais, non era un animal custoso para os seus donos, posto que lle abondaba con beber dúas veces ó día, e xantar un quilo de avea e cinco quilos de forraxe ou herba, que ademais podía encontrar nas beiras dos camiños (Mandianes 2002: 88).

Segundo explica Mandianes (Ibid.: 19), antigamente, no Oriente Próximo, onde se criaron os mellores exemplares de burros, quen posuía un rabaño deles gozaba de prestixio social, mesmo estaba regulado o seu comercio pola utilidade que supoñía para os campesiños. Por outra parte, na zona andina o burro era practicamente a única cabalería empregada para escalar dende vales ata cimeiras pola súa resistencia; tal e como explica o autor (Ibid.: 75): "ata o principio dos anos 70 só este tipo de cabalerías era quen de pasar polos camiños do val do Colca, no corazón dos Andes peruanos, situado a máis de 4000 metros de altitude". En Galicia o burro foi útil ata que chegaron os tractores e tamén os coches, pois as persoas atoparon outro método máis efectivo aínda para desenvolver os traballos que ata o momento eran propios do animal.

Pero a súa utilidade de outrora segue quedando latente en expresións como [ser] coma un burro atado a un poste ('torpeza') (LFCEG) en que se animaliza ó ser humano como 'torpe' a través da metáfora conceptual A PERSOA TORPE É UN BURRO: o feito de ter un burro atado a un poste supoñía estar desaproveitando o seu potencial para o traballo. Este potencial do burro para o traballo manifestouse, tamén, noutras expresións como [(andar/ir) cargado] coma un burro, [cargar] coma un burro, [cargar/traballar] coma unha/un burra/burro, burro de carga ou sofre o burro a carga mais non a sobrecarga, que recollemos baixo o ámbito temático de 'maltrato'.

Ademais, Mandianes (Ibid.: 75) engade que existen outras mostras de que o burro foi un animal apreciado nas casas galegas, pois tanto el coma outros animais frecuentemente ben valorados (o can ou a vaca, por exemplo) tiñan nome propio e eran considerados parte da familia, de maneira que, cando se vendía ou morría un deles, sentíase na casa familiar unha grande tristura.

\subsection{Valoración}

Canto á valoración que fan os galegos do burro rexistramos unicamente a mala valoración. Nas seguintes expresións o burro caracterizase como un ser desprovisto de valor ningún, tanto por ser considerado un estorbo como por tratarse dun transporte "de segunda", comparado co cabalo (un animal mellor valorado polos galegos). En todas elas prodúcese a animalización do ser humano nun burro mediante a metáfora conceptual A PERSOA INSIGNIFICANTE/ MOLESTA/DE MALA CONDICIÓN É UN BURRO:

- a carne de burro non é transparente (RESPOSTA: ollos de porco mírano todo): * 'dise cando alguén molesta nun determinado lugar, normalmente diante do noso campo visual' (RGMF, RGB, EE, EO)

- cando nace a vasoira, nace o burro que a roa: * 'fai referencia á unión ou vínculo entre persoas da mesma categoría ou condición [considerada normalmente baixa]' (RGB)

- de burro abaixo non hai menos besta/monta:* 'fai referencia á baixa estima que se lle ten a alguén ou a que non posúe unha boa posición social' (RGMF, RGB)

- o burro diante para que non se espante/para que a recua non espante: * 'dise cando alguén, ó facer unha enumeración de persoas, se coloca a si mesmo no primeiro lugar' (RGMF, RBG)

- val máis andar ca ornear: * 'indica que é mellor esforzarse para facer unha cousa ben, que deixala mal para acabar antes e correr o risco de ter que facela de novo' (RGMF)

A animalización do ser humano nun burro pode vir dada tamén mediante a metáfora conceptual os SENTIMENTOS, ESTADOS DE ÁNIMO, PENSAMENTOS E FACULTADES MENTAIS SON UN BURRO, sempre pensando na figura do burro como algo negativo:

\section{- levar un burro: ‘sufrir unha desilusión' (GDXL)}

As demais expresións figuradas non implican ningún proceso de animalización nin de personificación, pero a través delas podemos percibir a mala valoración que fan os galegos do burro:

- ter o burro á porta: 'ser obxecto de burla' (DFG)

- burro: '[despectivamente] cabalo de pouca calidade' (GDXL)

Outra expresión figurada en que se percibe a mala valoración que fan os galegos do burro é máis quero burro que me leva, que cabalo que me deixa ('eficacia') (RGMF). O contraste entre burro e cabalo que se establece nesta expresión só ten sentido nunha sociedade que 
valora negativamente o burro e na que o cabalo porta as valoracións positivas, pero que por razóns prácticas puntualmente pode optar polo animal peor valorado se lle resulta máis útil. A este respecto, Groba Bouza (2011: 158) explica que os galegos adoitan ver o cabalo como un ser nobre, probablemente polo status que lle proporciona a figura do xinete que o monta, mais esta concepción non deixa de ser, tal e como explica o autor, "imaxinería popular" que non conta, ademais, con ningunha base científica. Sexa como for, mediante a expresión máis quero burro que me leva, que cabalo que me deixa debemos entender que é preferible escoller o mellor dos considerados malos, antes do peor dos considerados bos para desenvolver un labor da maneira máis eficaz posible.

\section{Recompilación e análise das enquisas}

Despois analizar as 72 expresións figuradas galegas que teñen o burro como referente, comprobamos que os galegos destacan as seguintes características do seu carácter ou condición: 'estulticia' $\left(15^{21}\right)$, 'teimosía/insistencia' (7), 'gula' (4), 'agresividade' (3), 'rudeza/ brutalidade' (2), 'falsidade' ( $\left({ }^{22}\right)$, 'mansedume' (1), 'laboriosidade' (1) e 'fortuna' (123).

Canto ás características físicas do burro os galegos resaltan os valores de: 'grandura' (7), 'ruído' (4), 'fealdade' (1), 'resistencia' (1) e 'fortaleza' (1).

Polo que respecta ás relacións que se establecen entre o home e o animal os galegos salientan as características de: 'maltrato' (15) e 'utilidade' (1). Non rexistramos expresións figuradas que teñan como referente a relación que se poida establecer entre o burro e outros burros ou entre o burro e outros animais.

Por último, no apartado dedicado á valoración do animal sen ningún tipo de concreción, rexistramos a 'mala valoración' (9) do burro por parte dos galegos.

De xeito xeral, estes valores son comportados tanto por burro coma por burra, mais atopamos dous casos concretos en que só a burra funciona como referente: a 'falsidade' ([falso] coma unha burra vella / [máis falso] ca unha burra vella) e a 'fortuna' (vir a burra branca co diñeiro). No resto dos casos os valores son atribuídos tanto ó animal macho coma ó animal femia.

Ferro Ruibal (2008: 145) destaca que o burro ocupa en galego o décimo lugar na listaxe dos 20 referentes ou comparandos máis repetidos nas expresións comparativas do Tesouro Fraseolóxico Galego. Son 90 as ocorrencias en que figura este animal, das que 23 pertencen exclusivamente ó substantivo feminino burra. De acordo coas realidades que empregan os galegos para facer as súas comparacións, así como coas connotacións que teñen esas realidades, as características que sobresaen do burro nese corpus e que o autor destaca como positivas son as de 'paciente', 'traballador', 'resiste cargas' e 'pouco esperto' [sic]. O autor destaca como características neutras as de 'arrisca os dentes', 'griñe', 'orelludo', 'come moito' e 'calmoso a comer'. Por último, atópanse as características que Ferro Ruibal define como negativas: 'peideiro', 'terco', 'teimoso', 'coucea a traizón' e 'sexualmente activo'. Como se pode comprobar, coinciden coa nosa catalogación a maioría das particularidades referidas ó comportamento do animal, ás súas características físicas, á relación que ten co ser humano e á valoración que os galegos fan del.

Se nos centramos na caracterización que fan os galegos do burro a través das enquisas orais e electrónicas, en que os informantes ofrecen unha serie de adxectivos coa finalidade de caracterizar o burro e a burra, atopamos os seguintes resultados:

\section{Caracterización:}

- Carácter/condición: 'traballadores' $\left(101^{24}\right)$, 'parvos' (59), 'teimudos' (55 5 ), 'mansos/dóciles' $\left(29^{26}\right)$, 'tranquilos' (13), 'falsos' $\left(9^{27}\right)$, 'agarimosos' (8), 'intelixentes' (8), 'pacientes' (7), 'tristes' (5), 'fieis' (4), 'obedientes/submisos' (4), 'sacrificados' (3), 'parcos' (3), 'preguiceiros' (3), 'humildes' (2), 'simpáticos' (2), 'nobres' (2), 'indefensos' (1), 'independentes' (1), 'apoucados' (1), 'honrados' (1), 'resignados' (1), 'quentes' (1), 'pasivos' (1), 'desconfiados' (1), 'tenros' (1), 'miserables' (1).

\footnotetext{
Incidencia de aparición no corpus de expresións que indican esta característica.

Valor comportado soamente por burra.

Valor comportado soamente por burra.

Número de enquisas en que aparece esta valoración do burro.

Unha das respostas refírese concretamente ó animal femia, as demais respostas caracterizan os dous sexos.

Unha das respostas refírese concretamente ó animal femia, as demais respostas caracterizan os dous sexos.

Tres das respostas aluden explicitamente á burra, as demais fan referencia ós dous sexos.
} 
- Características fisicas: 'fortes' (16), 'lentos' (10), 'resistentes' (8), 'cansados' (4), 'torpes' (3), 'fermosos' (3).

Relacións:

- Home-animal: 'maltratados' (9), 'útiles' (2), 'compañeiros' (1).

Valoración:

- 'valiosos' (1).

Nesta mesma enquisa, en que os informantes responden con nomes de animais a unha serie de adxectivos e frases verbais, os galegos caracterizan o burro como un animal que 'leva a peor vida' (75), 'parvo/pouco intelixente' (56), 'falso' $\left(15^{28}\right)$, 'intelixente' (8), 'preguiceiro' (6), 'covarde' (3), 'fiel' (2), 'arrogante/fachendoso' (1).

Por último, os informantes tiveron que completar unha serie de expresións comparativas con nomes de animais e o burro destaca polos valores de 'manso' (20), 'feo' (10), 'pasa fame' (5), 'forte' (4), 'gordo' (3), 'puta’ $\left(1^{29}\right)$.

No que respecta ás características referidas ó carácter e á condición do burro, os resultados obtidos das enquisas orais e electrónicas coinciden coas expresións figuradas galegas analizadas nos valores de 'estulticia' (115), 'laboriosidade'(101), teimosía/insistencia'(55), 'mansedume/docilidade' (49) e 'falsidade' (24). Ademais, rexistramos nestas enquisas certas características que, aínda que non se extraian das expresións figuradas analizadas, si gardan certa relación $(>)$ cos valores que estas vehiculan: 'tranquilidade' (13), 'paciencia' (7), 'obediencia/submisión' (4), 'resignación' (1) e 'apoucamento' (1) (> 'mansedume/docilidade'); 'sacrificio' (3) (> 'laboriosidade'); 'fame' (5) (> gula): 'precariedade/mala vida' (75) (> 'maltrato').

Existen valores extraídos das expresións figuradas analizadas que non coinciden coa valoración feita polos informantes nas enquisas: 'agresividade', 'rudeza, brutalidade' e 'fortuna'. Do mesmo xeito, achamos outros valores que teñen representación nas enquisas, pero non nas expresións figuradas analizadas.
Trátase de valores como: 'benquerenza' (8), 'tristura' (5), 'covardía' (3), 'parquidade' (3), 'humildade' (2), 'nobreza' (2), 'simpatía' (2), 'quentura/fogosidade' (2), 'desconfianza' (1), 'honradeza' (1), 'indefensión' (1), 'independencia' (1), 'miseria' (1), 'pasividade' (1), 'arrogancia/fachenda' (1) e 'tenrura' (1). Por último, rexistramos unha serie de valoracións nas enquisas orais e electrónicas que se opoñen $(\neq)$ ás extraídas das expresións figuradas analizadas: 'intelixencia' (16) ( $\neq$ 'estulticia'), 'preguiza' (9) ( $\neq$ 'laboriosidade') e 'fidelidade' (6) ( $\neq$ 'falsidade'),

Canto ás características físicas do animal, coinciden entre as enquisas e as expresións figuradas os valores de 'fortaleza' (20), 'fealdade' (10) e 'resistencia' (8). Non rexistramos nas enquisas os valores de 'grandura' e 'ruído', que si tiñan representación nas expresións figuradas. Pola contra, nestas enquisas detectamos outros valores como a 'lentitude' (10), a 'gordura' (3) e a 'torpeza' (3), que non se rexistran nas expresións figuradas. Ademais, destaca o valor de 'fermosura' $(3)$ ( $\neq$ 'fealdade') co que se caracteriza o burro nas enquisas orais e electrónicas. Por último, os informantes das enquisas fan referencia ó 'cansazo' (4) do burro, un valor que garda directa relación $(>)$ coa nosa etiqueta de 'maltrato', baixo a que situamos expresións como [canso] coma un burro e burro cansado.

Polo que se refire ás relacións que se dan entre o home e o animal, coinciden os valores de 'maltrato' (9) e de 'utilidade' (2) que os galegos lle aplican ó burro tanto nas expresións figuradas recollidas coma nas enquisas orais e electrónicas; ademais, acrecéntase, nestas últimas, o valor de 'compañeirismo' (1). Ó igual ca nas expresións figuradas, tampouco recollemos nas enquisas realizadas valores vinculados coa relación do burro con outros animais.

Por último, a valoración directa do burro que fan os galegos nas enquisas non coincide en absoluto coa extraída das expresións figuradas, xa que os informantes o caracterizan como 'valioso' (1), mentres que nas expresións figuradas detectamos a 'mala valoración' do animal.

\footnotetext{
28 Unha resposta concreta refírese ó burro fariñeiro e dúas ó animal femia, as demais respostas fan referencia a ambos os dous sexos.

29 Este valor asociado ó animal femia.
} 


\section{Conclusións}

Podemos determinar, mediante esta análise, que os galegos caracterizan o burro como un animal estulto, pero útil para o traballo no campo e o transporte, pola súa resistencia, fortaleza e mansedume; aínda que ás veces mostre o seu carácter teimudo e, por iso, se comporte de xeito agresivo cos donos ó soltarlles falsamente algún couce. Por este motivo, os galegos empregan a violencia con el, posto que interpretan que o animal é preguiceiro e non quere traballar. Trátase, ademais, dun animal grande e robusto, polo que ás veces pode resultar un pouco brután. Polo mesmo motivo, os seus movementos son lentos e torpes, pero seguros; pois resulta ser a mellor montura para varios traballos agrícolas que requiren o paso por terreos difíciles. A pesar de que o animal non supón moito gasto para os seus donos, os galegos veno como un animal lambón, quizais por seguir comendo máis do que, a ollos do ser humano, merece. Para os galegos é un animal mal valorado, que fai ruídos molestos e feo. Así e todo, o burro é tamén ben valorado pola súa utilidade nas casas galegas, pois aínda que se lle apoñan todos estes defectos tamén destaca a súa fidelidade (ó igual ca no caso do can). Por moito que o maltraten este resiste pacientemente, cumpre no traballo da casa e non escapa $^{30}$. Son conscientes, tamén, da súa intelixencia, pois aprende máis rápido ca outros animais coma o boi, a vaca ou o cabalo; aínda que esta característica lles poida pasar desapercibida a moitas persoas por ser un animal de movementos lentos, algo que, unido ó feito de deixarse maltratar polo seu dono, determina a súa consideración de estulto.

Percibimos, como xa comentamos, certas características atribuídas ó animal (tiradas concretamente das enquisas orais e electrónicas) que difiren das que se viñan dando na tradición cultural galega. Cremos que o abandono do uso do burro (e do boi, da mula ou da vaca) para certos traballos agrícolas, así como a progresiva urbanización que sufriu a Galicia rural, propiciou que hoxe en día os galegos lle atribúan ó burro o valor da 'preguiza', pois xa non ten unha función determinada como a que tiña antano; do mesmo xeito, cobra sentido o valor de 'compañeirismo', xa que en moitas casas galegas pasou a ser un animal máis de compañía. Estes cambios sociolóxicos fan que os galegos vexan o burro dende unha óptica diferente, aínda que os informantes máis novos recoñezan expresións figuradas como [traballar] coma un burro e tamén as empreguen ${ }^{31}$. Relacionados coa concienciación da sociedade acerca do maltrato que sufriu o burro por moitos anos e a posta en valor das capacidades do animal para outro tipo de traballos (como a terapia para persoas con todo tipo de problemas psíquicos) atópanse os valores de 'intelixencia' e 'fidelidade'. Todos estes factores fan que a realidade de outrora, que motivou certas expresións figuradas co referente do burro, quede cada día máis afastada. A pesar diso, as expresións figuradas que acabamos de tratar aínda funcionan na sociedade actual cos mesmos significados cos que funcionaban cando se crearon e o burro segue a ser un dos referentes máis empregados na lingua galega para conceptualizar a realidade a través de expresións figuradas.

Ó igual que ocorre en galego, tamén noutras linguas o burro é un dos animais con máis presenza na fraseoloxía popular. Así o afirma Kioridis (2008: en liña) no estudo que fai dos refráns gregos e españois en que aparece reflectido o burro. $\mathrm{O}$ autor sinala que, tanto en grego coma en castelán, existen refráns que proxectan unha imaxe maioritariamente negativa do animal; unha imaxe que, tal e como explica o autor, "no se corresponde con sus cualidades ni con el valor extraordinario de las prestaciones que le da al hombre". O mesmo ocorre en francés, en que o burro adoita ser caracterizado, a partir das súas expresións figuradas, como un ser humilde, paciente, silencioso e que respecta o seu amo a pesar dos malos tratos que este lle dá e os castigos que lle impón. Nesta lingua, tal e como ocorre en galego, o nome do burro foi, dende tempos antigos, sinónimo da ignorancia e da estupidez; o animal doméstico que presentaba a peor reputación na linguaxe figurada francesa (Rozan 1902: 19-43).

\footnotetext{
30 Mariño Ferro (1996: 37) explica que o burro destaca na cultura occidental por ter un carácter plácido e paciente, que lle permite soportar os malos tratos coa maior resignación.

31 E o caso de máis de trinta informantes das enquisas de entre 13 e 30 anos.
} 
Cascajero Garcés (1998: 14) repara na dualidade temática das valoracións que o ser humano fai do burro e explica que, a pesar da mala valoración que se lle daba a este animal en España, constituía un auxiliar elemental e básico para os aldeáns; excluídos, iso si, outros animais máis custosos coma o boi, o mulo ou o cabalo que un campesiño moitas veces non podía pagar. $\mathrm{O}$ autor mostra certas calidades positivas do burro a pesar da súa mala reputación:

Soporta el calor y la sequía mejor que caballos (no muy usados, generalmente, en la Antigüedad, para el trabajo) y mulos. Era mucho más sobrio y frugal en su alimentación, más austero, paciente y sufrido, más dócil, manso y obediente, más humilde, laborioso y quieto, más resistente a la enfermedad, más longevo, más barato, sin necesidad de herrajes, ni albardas ni cinchas ni aparejos (aunque los agradezca). Superior a ellos, también, en energía, poder nervioso, tenacidad en el trabajo, temperamento y resistencia a la fatiga y, sin duda, según nos parece, dotado de mayor inteligencia. (Cascajero Garcés 1998: 15)

O burro parece ser, xa que logo, un animal desafortunado tanto na nosa tradición cultural, coma na doutras linguas. Non deixa de resultar curioso como un animal que presenta tantas calidades útiles para as persoas, sexa un dos peor valorados, aínda que se recoñeza, de xeito minoritario, a súa utilidade. Cremos que o punto de partida da mala valoración que galegos fan do burro, comportada polas características de 'estulticia', 'agresividade', 'falsidade', 'fealdade' etc., garda relación co feito de que sexa unha montura barata, a única que se podían permitir as casas pobres. Normalmente as persoas con máis posibilidades económicas non tiñan burros, senón outro tipo de monturas máis custosas, coma cabalos ${ }^{32}$. A idea de que aquilo que é accesible a todos é de mala calidade, mentres que o que só está a disposición duns cantos é de boa calidade, inflúe no feito de que en Galicia se asocie o burro coa pobreza $^{33}$, coa precariedade e coa mala vida; aínda que, como comprobamos, as calidades positivas que presenta o animal sexan moitas. Cremos que, unha vez que se forma esa imaxe negativa do burro, as demais características que posúe, que en principio deberían ser valores neutros (como a lentitude), comezan a ser interpretadas tamén de xeito negativo e asociadas con outras (coma a estulticia ou a teimosía). Deste xeito, un animal probadamente intelixente (Mandianes 2002: 88) remata por converterse nun símbolo de estulticia na nosa sociedade.

\section{Referencias bibliográficas}

Álvarez de la Granja, María (2011): "Agudo coma un allo o burro cego. La conceptualización de la inteligencia y de la estulticia a través del lenguaje figurado gallego", en Stefana Bojanova Kaldieva-Zaharieva e Radostina Zaharieva (eds.): Linguistic studies in honour of Prof. Siyka Spasova-Mihaylova. Sofía: Bulgarian Academy of Sciences / Institute for Bulgarian Language, pp. 377-413.

Burnie, David (ed.) (2002): Grande enciclopédia animal. Porto: Civilização.

Carballeira Anllo, Xosé María (coord.) (2009): Gran dicionario Xerais da lingua. Vigo: Xerais, 2 vols.

Casal Vila, Benxamín (dir.) (2003): Gran enciclopedia galega Silverio Cañada. Lugo: El Progreso/Diario de Pontevedra.

Cascajero Garcés, Juan (1998): “Apología del asno. Fuentes escritas y fuentes orales tras la simbología del asno en la Antigüedad", Gerión 16, pp. 11-38.

Cruz Cabanillas, Isabel de la e Cristina Tejedor Martínez (1998): "La metaforización de algunas denominaciones genéricas de animales”, en José Luis Cifuentes Honrubia (ed.): Estudios de Lingüística Cognitiva I. Alicante: Universitat d'Alcant, pp. 381-388.

Echevarría Isusquiza, Isabel (2003): “Acerca del vocabulario español de la animalización humana”, Círculo de Lingüística Aplicada a la Comunicación 15, http://pendientedemigracion.ucm.es/info/circulo/no15/ echevarri.htm [consulta: 17/02/2019].

32 Groba Bouza (2011: 158) explica que a suposta ignorancia do burro é un falso estigma da sociedade e basea a súa explicación na comparación que fan os humanos do burro co cabalo.

33 Mariño Ferro (1996: 37) descríbeo como un animal "Sobrio, poco exigente, trabajador: el animal apropiado para los pobres. Incluso podríamos decir que pobres y asnos comparten esas cualidades, además del aspecto humilde que los diferencia, respectivamente, de los señores y de los caballos". 
Ferreira Guerra, Rogerio (2011): "Os animais na fraseologia brasileira", Revista de Ciências Humanas Florianópolis 45/2, pp. 461-515.

Ferro Ruibal, Xesús (1995): Refraneiro galego básico. Vigo: Galaxia. (2002): Refraneiro galego máis frecuente. Vigo: La Voz de Galicia.

(2006): "Locucións e fórmulas comparativas ou elativas galegas", Cadernos de fraseoloxía 8, pp. $179-265$.

— (2008): “A comparación fraseolóxica galega como radiografía lingüística”, en María Álvarez de la Granja (ed.): Lenguaje figurado y motivación: una perspectiva desde la fraseología. Frankfurt am Main: Peter Lang, pp. 129-189.

González González, Manuel (dir.) (2012): Dicionario da Real Academia Galega, http://www.realacademiagalega.gal/ [consulta: 17/02/2019].

Groba Bouza, Fernando (2011): "Onde hai eguas, poldros nacen. A realidade vista dende os equinos", $\mathrm{Ca}$ dernos de Fraseoloxía Galega 13, pp. 149-176.

Iñesta Mena, Eva María e Antonio Pamies Bertrán (2002): Fraseología y metáfora: aspectos tipológicos y cognitivos. Granada: Granada Lingüística.

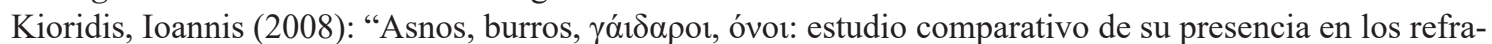
nes españoles y griegos”, Culturas Populares. Revista electrónica 6, http://www.culturaspopulares.org/ textos6/articulos/kioridis.pdf.

Lakoff, George e Mark Johnson (1980): Metaphors We Live By. Chicago: University of Chicago Press.

López Taboada, Carme e María Rosario Soto Arias (2008): Dicionario de fraseoloxía galega. Vigo: Xerais. Mandianes Castro, Manuel (2002): O burro. Vigo: Ir Indo.

Mariño Ferro, Xosé Ramón (1985): La medicina popular interpretada, vol. 1. Vigo: Xerais.

(1996): El Simbolismo animal: creencias y significados en la cultura occidental. Madrid: Encuentro.

Martín Zorraquino, María Antonia (1986): "Sobre algunas expresiones fijas con nombres de animal en el español coloquial moderno”, en Estudios en homenaje al Dr. Antonio Beltrán Martínez. Zaragoza: Universidad de Zaragoza, pp. 1259-1263.

Martínez Seixo, Ramón Anxo (dir.) (2000): Dicionario fraseolóxico galego. Vigo: A Nosa Terra.

Perozo Ruiz, Xosé Antonio (dir.) (1999): Enciclopedia galega universal, t. 4. Vigo: Ir Indo.

Piñel López, Rosa María (1999): "El animal en el refrán, reflejo de una cultura. Estudio contrastivo alemánespañol”, Paremia 8, pp. 411-416.

Pose Nieto, Herminio (2008): “Galicia, terra de équidos”, en Diego Conde Gómez e José Manuel Vázquez Varela, Os animais domésticos na historia de Galicia. A Coruña: TresCtres.

Quintáns Suárez, Manuel (dir.) (1997): Diccionario conceptual galego. A Coruña: Xuntanza, 8 vols.

Rivas López, Francisco (2005): Dicionario fraseolóxico do mar: así falan os mariñaos. Vigo: A Nosa Terra.

Rozan, Charles (1902): Les animaux dans les proverbes. Paris: Ducrop.

Santamarina Fernández, Antón (2003) (coord.) (2003): Dicionario de dicionarios, http://sli.uvigo.es/DdD/ [consulta: 17/02/2019].

Santos Domínguez, Luis Antonio e Rosa María Espinosa Elorza (1996): Manual de semántica histórica. Madrid: Síntesis.

Szalek, Jerzy (2005): "Los colores y su semántica en las expresiones fraseológicas españolas", Studia Romanica Posnaniensia 32, pp. 87-96.

Taboada Chivite, Xesús (2000): Refraneiro galego. (Cadernos de fraseoloxía galega 2). Xunta de Galicia: Centro Ramón Piñeiro para a Investigación en Humanidades, https://www.cirp.gal/w3/publicacions/ pub-0059.html.

Vázquez Saco, Francisco (2003): Refraneiro galego e outros materiais da tradición oral. (Cadernos de fraseoloxía galega 5), Xunta de Galicia: Centro Ramón Piñeiro para a Investigación en Humanidades, https://www.cirp.gal/w3/publicacions/pub-0142.html.

Vyshnya, Natalia e María Ángeles García Jove (2005): "Simbolismo de las paremias con el elemento animal en español y ucraniano", Paremia 14, pp. 193-201. 